\title{
Common Medicinal Plants as Repellents against Stored Grain Insects- Sitophilus oryzae and Tribolium castaneum
}

\author{
Dr.Dhaniya M.V.* ${ }^{1}$ and Dr. Susha Dayanandan ${ }^{2}$ \\ ${ }^{l}$ Department of Zoology, University College, Thiruvananthapuram - 695034. \\ ${ }^{* 2}$ Department of Zoology, Mar Ivanios College, Thiruvananthapuram, Kerala, India - 695015
}

\section{Introduction}

Plant powders were traditionally used as grain protectants (Isman, 2000, rajasekhar et al, 2012). The mode of action of plant powders may vary but with low to moderate dosages, the effect is repellant or toxic (Rajapakse, 2006). Salvadores et al(2007) showed that powders of P.nigrum, Cinnammomum annum and Cinnammommum zeylanicum had a repellent effect on Sitophilus zeamais. In the study, at higher concentrations 100 percent mortality was achieved. Roots of Inulara cemosa showed high repellence to Sitophilus oryzae and also had strong insecticidal activities against the weevil (Liu et al, 2006). The use of plant powders is the simplest method of grain protection. However, extracting plant material with an appropriate solvent usually results in the concentration of the ingredients. These extracts are generally mixed with the grains in a liquid form, from which the solvent is evaporated completely before storing. Aqueous extract of Lantana camara was found to reduce infestation of tea leaves by the tea mosquito bug Heopellis theivora (Deka et al, 2001). Organic plant extracts are also reported to be effective against insects. In a study, among petroleum ether, acetone and ethanol extracts of turmeric used, acetone extracts was reported to act as the best repellent and growth inhibitor against B.zonata (Siddiqui et al, 2006).

Sitophilus oryzae L. and Tribolium castaneum $\mathrm{H}$. are serious pests of stored grains having a worldwide distribution. Both larval and adult stages of the insects are destructive to stored products. The present study examines the repellency and toxicity of four common medicinal plants and a fern namely Lantana camara, Hyptis sauveolens, Citrus medica, Aegle marmelos and Lygodium flexosum against the two stored grain pests.

\section{Sitophilus oryzae}

\section{Materials And Methods}

Sitophilus oryzae is commonly known as rice weevil. It is a very serious major pest of stored rice and other cereals in the warmer parts of the world. The rice weevil is a small dark brown weevil with a long snout. The female weevil bores a tiny hole in the grain kernel and deposits an egg inside. The adult weevil emerges from the pupa and cuts an exit hole to emerge. Sometimes the adult lays eggs in the surface of the grains and the larvae can be seen outside the kernels. In rice the entire grain is usually destroyed by the time the adult emerges.

\section{Tribolium castaneum}

Tribolium castaneum is commonly known as red flour beetle. It is a worldwide stored product pest. Red flour beetles have chewing mouthparts, but do not bite or sting. Red flour beetles attack stored grain products causing serious damage. The beetle life cycle lasts about three years or more. The female flour beetle lies about 300-400 eggs during its life cycle. The beetles give off an unpleasant smell, and their presence encourages mould growth in flour.

\section{Medicinal plants used for the study}

L. camara, H. sauveolens, C. medica, A. marmelos, L.flexosum, plant leaves have collected and prepared the leaf powder and also aqueous and ethanol extracts were made from these powders using distilled water and ethanol as solvents.

\section{Culture of insects}

Adults from the stock culture were collected and deposited in separate culture bottles and kept for 2-3 days, so that the insect may lay eggs. After three days the adults were removed and the culture bottles were kept in the laboratory. The adults that emerged from the eggs in the culture from this bottle were considered as newly emerged. These newly emerged adults were used to study the repellent activity of plant powder and plant extracts. 


\section{Treatments with Improvised apparatus}

An apparatus was designed with some modifications (Prakash and Rao, 2006) to study the adult deterrence. Materials used to make the apparatus were a plastic container; two plastic plates and seven glass beakers. The feed were taken in the glass beakers. In six beakers feed was mixed with the leaf powders and one beaker in the centre was kept vacant without adding either feed or leaf powder in it. The experiment was conducted in such a way that different concentrations of the leaf powders were tried at the same time or same concentration of the different plants was tried at the same time. 40 newly emerged adults were deposited in the middle beaker and the lid kept closed. The changes in the set up was analysed at particular intervals i.e. 1, 2, 3, 4 , and 24 hours.

Calculation of percentage repellency:

Percentage repellency was calculated by the method described by Laudani et al. (1955):

Repellency $=[C-T] \div[C] \times 100$

Where $\mathrm{T}=$ mean number of msects on treated beaker; $\mathrm{C}=$ mean number of insects on control beaker Percentage repellency of the insects against different plant extracts at different concentrations has been observed. It was clear that both the insects, S.oryzae and T.castaneum, showed repellency against all the five plant powders. There was no significant difference in the percentage repellence among the insects i.e in the plant powders against S.oryzae and T.castaneum. At all the doses tried the repellency reached above $60 \%$. It reached up to $95 \%$ in certain doses.

\section{Sac method}

Cloth sacs were made and they were soaked in liquid aqueous extracts of various concentrations $(5 \%$, $6 \%, 7 \%, 8 \%, 9 \%$ and 10\%) and allowed to dry. Then the $20 \mathrm{gm}$ feed (raw rice and wheat flour) and 10 adult insects each were deposited in the sac and the mouths of the sacs were tied with thread. The experimental set up were kept for seven days and observed every day up to 7 days. Control was also prepared in the same way. Instead of soaking the sacs in aqueous extracts the sacs used for control set up was soaked in distilled water and allowed to dry. 5 replicates each were kept for control and experimental set up.

\section{Observation And Results}

\section{Repellency in S.oryzae when treated with different leaf powders}

The percentage repellency was $80 \%$ at the doses $5 \%, 6 \%$, and $7 \%$ of L.camara leaf powder while it was $75 \%, 70 \%$ and $72 \%$ respectively at the doses $8 \%, 9 \%$ and $10 \%$.

The percentage repellency was $75 \%$ at the dose $5 \%$ and it was $76 \%$ at the dose of $6 \%$ of H.sauveolens leaf powder. The repellency rate in S.oryzae reached $70 \%$ when treated with $7 \%$ dose leaf powder of H.sauveolens. The treatment of $9 \%$ and $10 \%$ dose of H.sauveolens resulted in the percentage repellency as $72 \%$ and $68 \%$ respectively.

The percentage repellency was $75 \%$ at the dose $5 \%$ of $C$.medica leaf powder while it was $80 \%$ when treated with $6 \%$ dose of C.medica leaf powder. The repellency rate was $70 \%$ when treated with $7 \%, 8 \%, 9 \%$ and $10 \%$.

The repellency rate of S.oryzae when treated with the 5\% dose of A.marmelos leaf powder was recorded as $73 \%$. When the S.oryzae were treated with the $6 \%$ dose of A.marmelos leaf powder the repellency rate was $66 \%$. The repellency rate was $70 \%$ when treated with the $7 \%$ and $9 \%$ dose leaf powder of A.marmelos. The repellency rate of S.oryzae when treated with $8 \%$ dose leaf powder of A.marmelos was observed as $72 \%$. The repellency rate was observed as $68 \%$ when treated with the $10 \%$ dose leaf powder of A.marmelos.

The repellency rate in S.oryzae was 70\% when treated with the 5\% dose leaf powder of L.flexosum. When the S.oryzae adults were treated with $6 \%$ and $8 \%$ dose leaf powder of L.flexosum the repellency rate was $72 \%$. The repellency rate was observed as $73 \%$ when treated with the $7 \%$ and $9 \%$ dose leaf powder of L.flexosum. The repellency rate was $70 \%$ when treated with the $10 \%$ dose leaf powder of L.flexosum.

\section{Repellency in T.castaneum when treated with different leaf powders}

The percentage repellency was $80 \%$ when treated with 5\% dose of L.camara leaf powder, while it was $70 \%$ when treated with the $6 \%$ and $7 \%$ dose leaf powder. The percentage repellency was $68 \%$ when treated with $8 \%, 9 \%$ and $10 \%$ dose of L.camara leaf powder.

The repellency was $70 \%$ when treated with $5 \%$ dose of $H$.sauveolens leaf powder. The repellency rate was $73 \%$ when treated with $6 \%$ dose of $H$. sauveolens. The repellency rate was $66 \%$ when treated with $7 \%$ dose leaf powder. When treatment have done with the $8 \%$ dose of H.sauveolens the repellency was $65 \%$ when treated with $8 \%$ dose of H.sauveolens leaf powder. The percentage repellency was $72 \%$ and $73 \%$ when treated with $9 \%$ and $10 \%$ dose respectively. 
The percentage repellency was recorded as $80 \%$ when treated with $5 \%$ dose leaf powder of C.medica. When $6 \%$ dose of Leaf powder of C.medica leaf powder was used for the treatment the repellency rate was $73 \%$. The repellency rate was recorded as $75 \%$ and $72 \%$ respectively when the $7 \%$ and $8 \%$ dose leaf powder of C.medica was used for the treatment. The repellency rate was $68 \%$ when treated with $9 \%$ dose leaf powder. The repellency rate was $64 \%$ when T.castaneum treated with the $10 \%$ dose leaf powder of C.medica.

The repellency rate of T.castaneum when treated with the 5\% dose of A.marmelos leaf powder was recorded as $60 \%$. When the T.castaneum were treated with the $6 \%$ dose of A.marmelos leaf powder the repellency rate was $70 \%$. The repellency rate was $95 \%$ when treated with the $7 \%$ dose leaf powder of A.marmelos. The repellency rate of T.castaneum when treated with $8 \%, 9 \%$ and $10 \%$ dose leaf powder of A.marmelos was observed as $73 \%$.

The repellency rate in T.castaneum was $70 \%$ when treated with the $5 \%$ dose leaf powder of L.flexosum. When the T.castaneum adults were treated with $6 \%$ dose leaf powder of L.flexosum the repellency rate was $60 \%$. The repellency rate was observed as $72 \%$ when treated with the $7 \%, 8 \%$ and $9 \%$ dose leaf powder of L.flexosum. The repellency rate was $68 \%$ when treated with the $10 \%$ dose leaf powder of L.flexosum.

\section{Effect of aqueous extract on S.oryzae}

At the doses $5 \%, 6 \%, 7 \%, 8 \%, 9 \%$ and $10 \%$ L.camara aqueous extract, the number of insects found dead were observed to be $1,1,2,2,3$, and 3 , respectively.

At the doses $5 \%, 6 \%, 7 \%, 8 \%, 9 \%$ and $10 \%$ H.sauveolens aqueous extract, the number of insects found dead were observed to be $1,2,2,2,3$, and 4 , respectively.

At the doses $5 \%, 6 \%, 7 \%, 8 \%, 9 \%$ and $10 \%$ C.medica aqueous extract, the number of insects found dead were observed to be $1,1,2,3,3$, and 3 , respectively.

At the doses 5\%,6\%,7\%,8\%, 9\% and 10\% A.marmelos aqueous extract, the number of insects found dead were observed to be $1,2,2,4,4$, and 4 , respectively.

At the doses $5 \%, 6 \%, 7 \%, 8 \%, 9 \%$ and $10 \%$ L.flexosum aqueous extract, the number of insects found dead were observed to be $1,2,2,3,3$, and 3 , respectively.

\section{Effect aqueous extract on $\boldsymbol{T}$. Castaneum}

At the doses $5 \%, 6 \%$ and $7 \%$ of L.camara aqueous extract, no mortality was observed in T.castaneum adults while at $8 \%, 9 \%$ and $10 \%$ the number of insects found dead were observed to be 1,2 and 3 respectively.

At the doses $5 \%$ and $6 \%$ of H.sauveolens aqueous extract, no mortality was observed in T.castaneum adults while at $7 \%, 8 \%, 9 \%$ and $10 \%$ the number of insects found dead were observed to be $1,1,2$ and 3 respectively.

At the doses 5\%,6\% and 7\% of C.medica aqueous extract, no mortality was observed in T.castaneum adults while at $8 \%, 9 \%$ and $10 \%$ the number of insects found dead were observed to be 1,3 and 3 respectively.

At the doses 5\%, 6\% and $7 \%$ of A.marmelos aqueous extract, no mortality was observed in T.castaneum adults while at $8 \%, 9 \%$ and $10 \%$ the number of insects found dead were observed to be 2,4 and 5 respectively.

At the doses 5\%,6\% and 7\% of L.flexosum aqueous extract, no mortality was observed in T.castaneum adults while at $8 \%, 9 \%$ and $10 \%$ the number of insects found dead were observed to be 2, 3 and 5 respectively.

\section{Effect of ethanolic extract on S.oryzae}

At the doses 5\%,6\%,7\%,8\%,9\% and $10 \%$ L.camara aqueous extract, the number of insects found dead were observed to be $1,2,2,3,3$, and 3 , respectively.

At the doses $5 \%, 6 \%, 7 \%, 8 \%, 9 \%$ and $10 \%$ H.sauveolens aqueous extract, the number of insects found dead were observed to be $1,2,2,3,3$, and 3 , respectively.

At the doses 5\%,6\%,7\%,8\%,9\% and 10\% C.medica aqueous extract, the number of insects found dead were observed to be $1,1,2,2,4$, and 4 , respectively.

At the doses $5 \%, 6 \%, 7 \%, 8 \%, 9 \%$ and $10 \%$ A.marmelos aqueous extract, the number of insects found dead were observed to be $2,2,2,3,2$, and 4 , respectively.

At the doses $5 \%, 6 \%, 7 \%, 8 \%, 9 \%$ and $10 \%$ L.flexosum aqueous extract, the number of insects found dead were observed to be $1,2,2,3,3$, and 4 , respectively.

\section{Effect ethanolic extract on T.castaneum}

At the doses $5 \%$ and $6 \%$ of L.camara aqueous extract, there was no mortality in T.castaneum adults while at $7 \%, 8 \%, 9 \%$ and $10 \%$ the number of insects found dead were observed to be 1, 2, 2 and 4 respectively.

At the doses $5 \%, 6 \%$ and $7 \%$ of H.sauveolens aqueous extract, there was no mortality in T.castaneum adults while at $8 \%, 9 \%$ and $10 \%$ the number of insects found dead were observed to be 1,2 and 2 respectively. 
At the doses $5 \%, 6 \%, 7 \%, 8 \%, 9 \%$ and $10 \%$ C.medica aqueous extract, the number of insects found dead were observed to be $1,1,2,3,4,5$, respectively.

At the doses $5 \%$ and $6 \%$ of $H$.sauveolens aqueous extract, there was no mortality in T.castaneum adults while at $7 \%, 8 \%, 9 \%$ and $10 \%$ the number of insects found dead were observed to be 2, 3, 4 and 5 respectively.

At the doses $5 \%, 6 \%$ and $7 \%$ of L.flexosum aqueous extract, there was no mortality in T.castaneum adults while at $8 \%, 9 \%$ and $10 \%$ the number of insects found dead were observed to be 1,3 and 4 respectively.

\section{Discussion}

Strong insect repellent activity noted in all the plants used in the study, indicate the presence of active compounds in the plant components and hence indicate promising sources of plant based insecticides. There are several reports of such phytochemicals influencing the life and behaviour of insects. Larvae are suggested to be more susceptible than adult insects (Koul and Isman, 1991; Jagannath and Nair, 1992). Plant species have been reported to be effective against insects either by direct effects on the growth and development or reduced feeding by acting on receptors. Fresh and dry leaves of C.aequalis were reported to emit strong persistant aromatic odours repellant to weevils (Parhetel, 1998; Ntonifer and Monah, 2001). Entire or powdered fruits of Piper spp. have insecticidal and repulsive effect against many pests (Ntonifer and Monah, 2001). Biologically active flavonoids identified in hydro ethanolic extracts of Inula racemosa (Pachew - Sanchz et al, 2013) were believed to be responsible for the high repellence and strong insecticidal activities of the plant against S.oryzae (Liu et al, 2006). Contact toxicity of many plant powders to insect pests and repellency effects have been demonstrated (Boeks et al, 2004). It is indicated that plant powders may act as repellent, fumigant, stomach poison and physical barrier, blocking the spiracles and insairing respiration (Law - Ogbomo and Enobakhare, 2007; Mulungu et al, 2007).

About 2000 plants are reported to possess some type of antifeedant, repellent or insecticidal compounds (Bouda et al, 2001). Since the plants used in this study are medicinal, they are quite safe for human consumption and thus can be included in any pest control strategy. However, further work aimed at isolation of the specific compounds acting against the insects and nature of the effects of the compounds at the cellular level would be interesting.

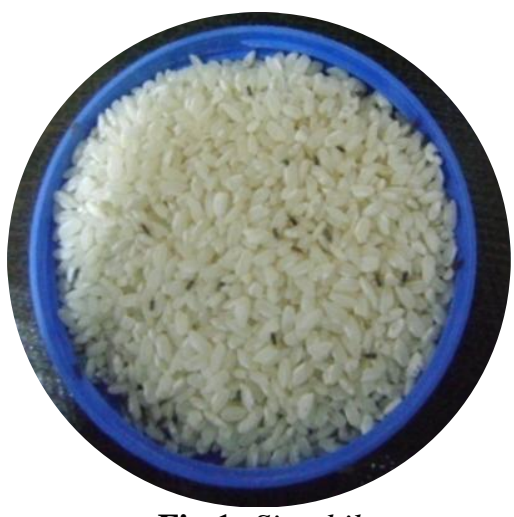

Fig 1: Sitophilus oryzae

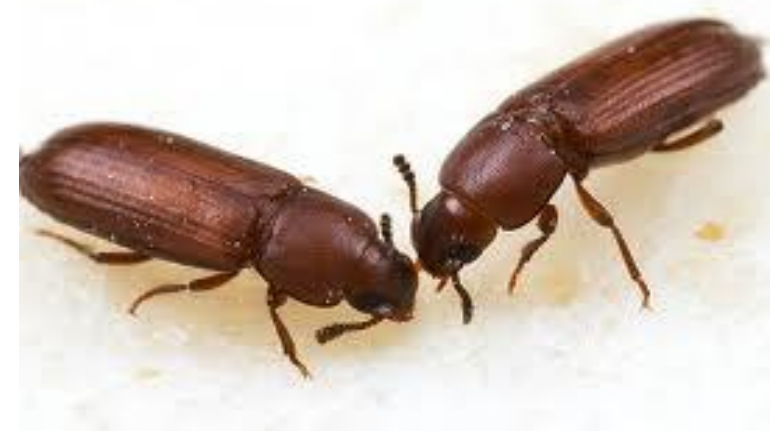

Fig 2: Tribolium castaneum

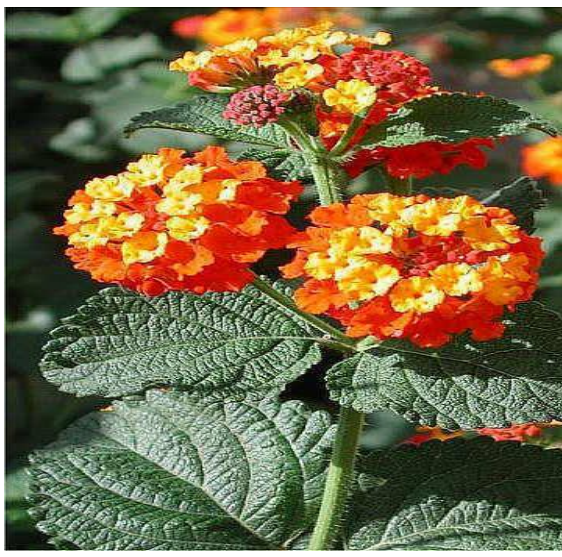

Fig 3: Lantana camara

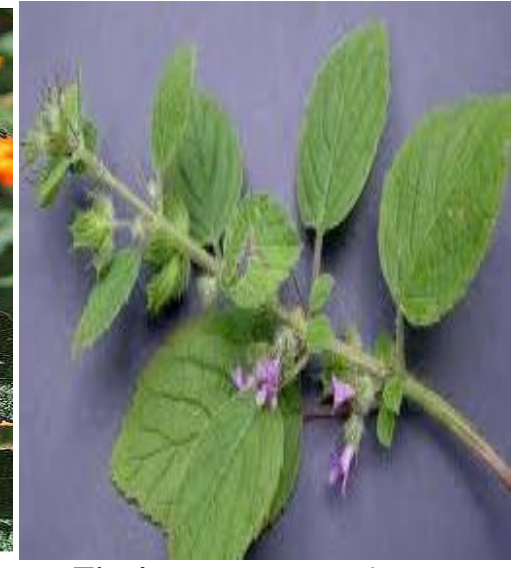

Fig 4: Hyptis sauveolens

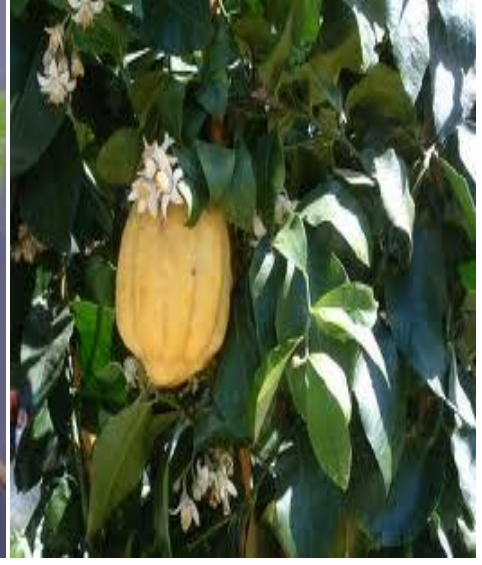

Fig 5: Citrus medica 


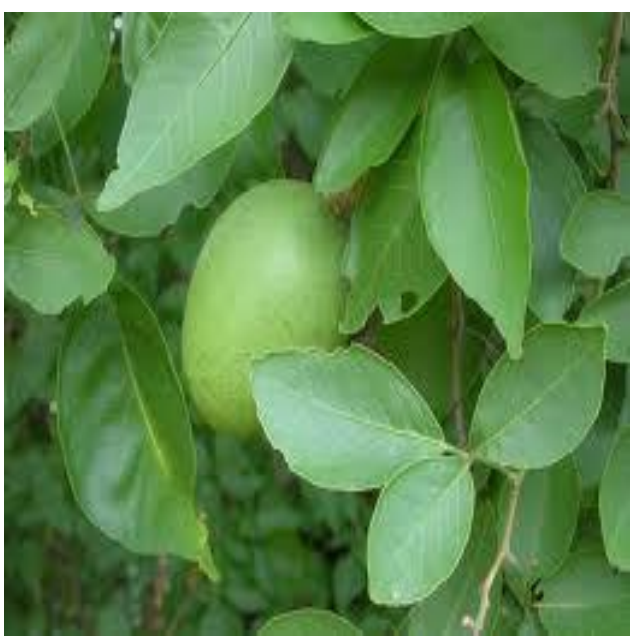

Fig 6: Aegle marmelos

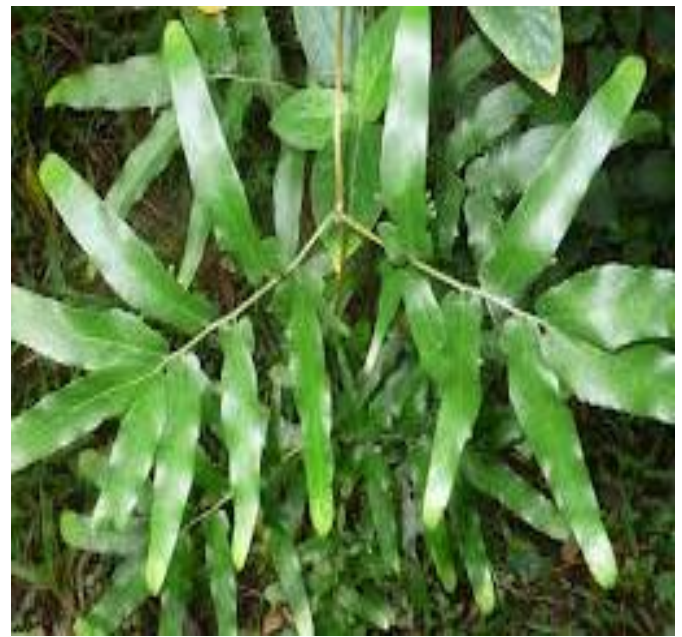

Fig 7: Lygodium flexosum
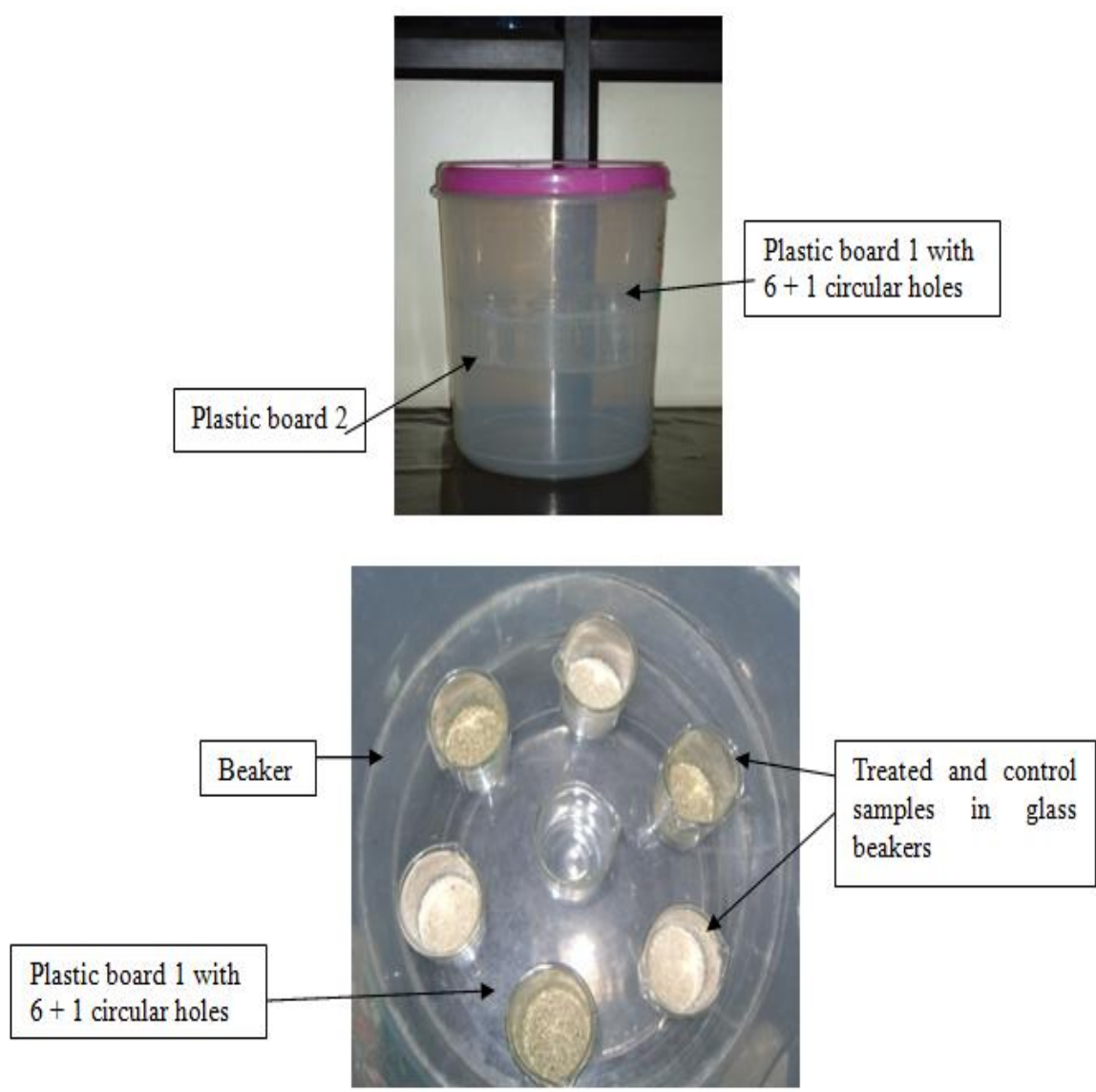

Fig 8: An apparatus was designed for treating insects with plant extract

Table 4.1.1: Percentage repellency of L.camara leaf Powder against S.oryzae and T.castaneum

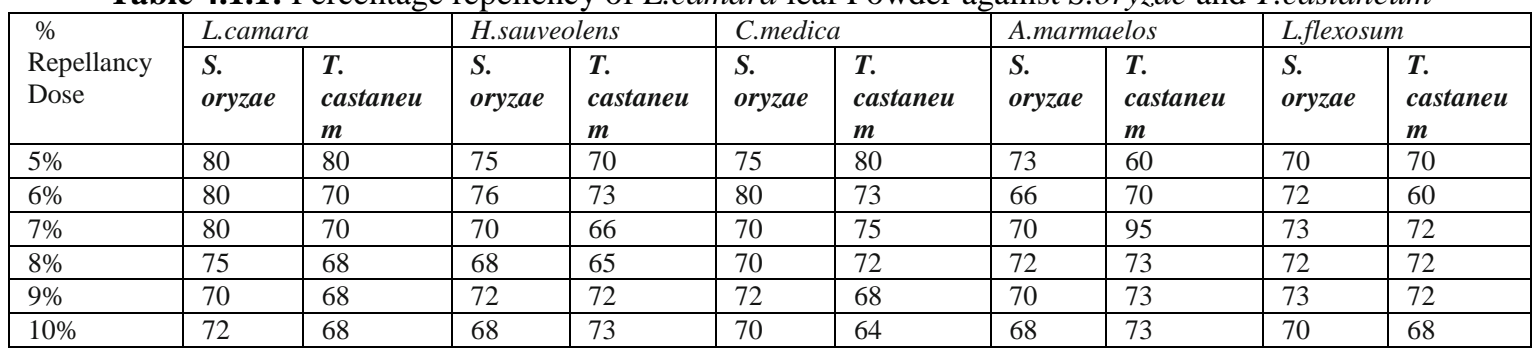



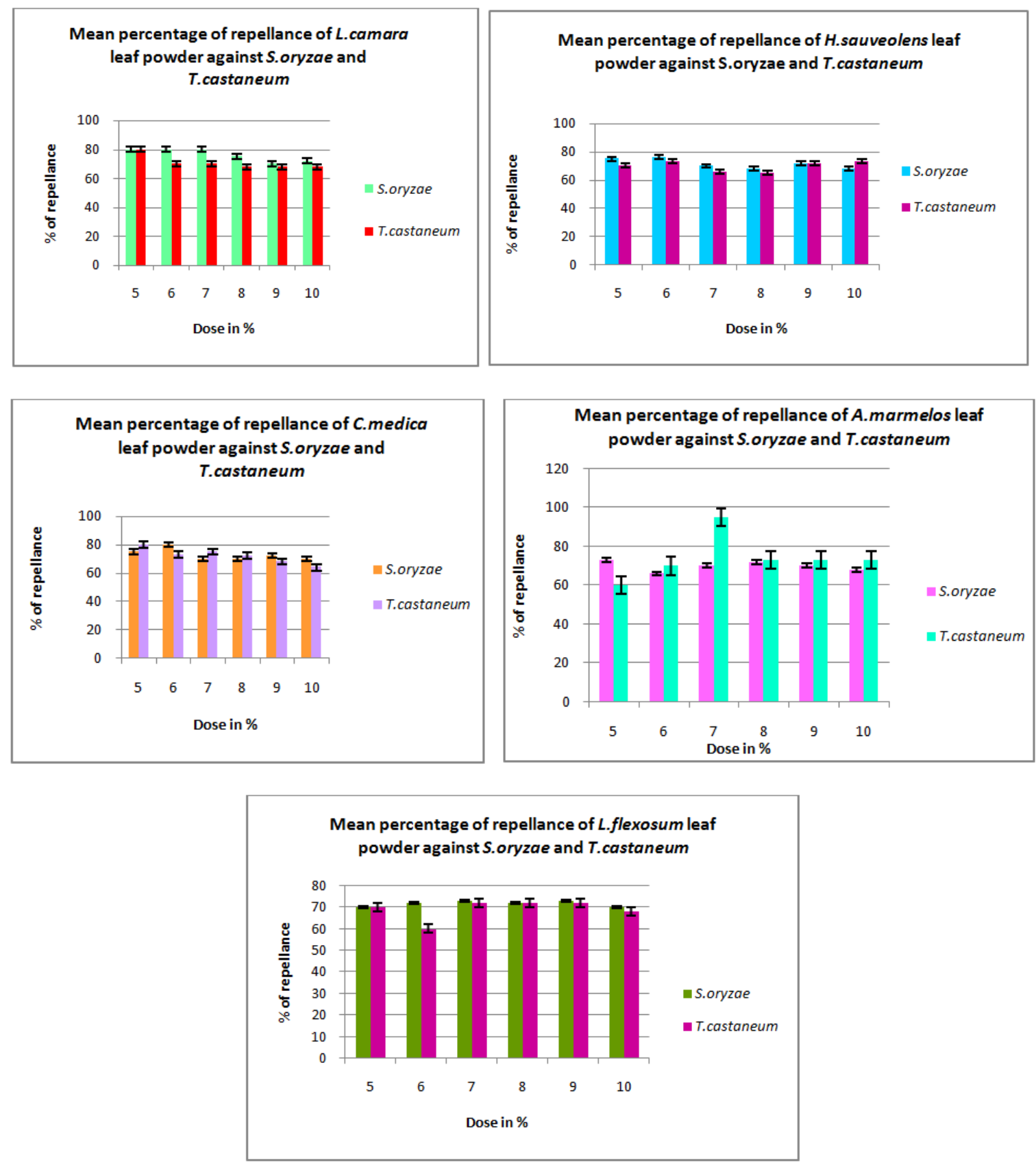

\section{References}

[1]. Isman, M.B. 2000. Plant essential oils for pest and disease management. Crop Protection. 19. 603-08.

[2]. Rajashekar, Y., Bakthavatsalam, N. and Shivanandappa, T. 2012. Botanicals as grainprotectants. Psyche, 2012: 1-13.

[3]. Rajapakse, R.H.S. 2006. The potential of plants and plant products in stored insect pest management. The Journalof Agricultural Sciences 2, 11-21.

[4]. Salvadores, U. Y., Silva, A. G., Tapia V. M., Hepp G. R. 2007. Polvos de especiasaromáticas para el control delgorgojo del maíz, SitophiluszeamaisMotschulsky, en trigoalmacenado. Agriculturatécnica (Chile): 67.147-154.

[5]. Liu, C.H., Mishra, A.K. and Tan, R.X. 2006. Repellent, insecticidal and phytotoxic activities of isoalantolactone from Inularacemosa. Crop Protection 25(5):508-511.

[6]. Deka, M. K., Singh, Karan, Handique, R. and Singh, K.2001. Efficacy of wild sage (Lantana camara L.) and Basak (Adhatodavasica) against tea mosquuito bug, Helopeltistheivora in the field. Research on Crops, 2(1): 66-70.

[7]. Siddiqi, A.R., Jilani, G., Rehman, J.U. and Kanvil, S. 2006. Effect of turmeric extracts on settling response and fecundity of peach fruit fly (Diptera: Tephritidae).Pakistan J. Zool. 38. 131-135.

[8]. Prakash A.and Rao J. 2006. Exploitation of newer botanicals as rice grain protectants against angoumois grain moth SitotrogacerealellaOliv. Entomon,31: 1-8.

[9]. Koul, O, and Isman, M. B. 1991. Effects of azadirachtinon the dietary utilization and development of the variegated cut worm, Peridromasaucia; J.Insect Physiol. 37.591-598.

[10]. Jagannadh, V. and Nair, V.S.K. 1992. Azadirachtin - induced effects on larval - pupaltransformation of Spodopteramauritia. Physiol. Entomon., 17:56-61.

[11]. Ntonifor, N.N. and Monah, I.M. 2001. Use of three spices to protect stored maize against Sitophiluszeamis. Trop. Sci., 41: 74-77. 
[12]. Pacheco-S ánchez, C., Villa-Ayala, P., Montes-Bel-Mont, R., Figueroa-Brito, R. and Jiménez-Pérez, A. 2012. Effect of Ricinuscommunis extracts on weight and mortality of Scyphophorusacupunctatus (Coleoptera: Curculionidae). I. J. Appl. Sci. Tech. 2: 83-94.

[13]. Liu, C.H., Mishra, A.K. and Tan, R.X. 2006. Repellent, insecticidal and phytotoxic activities of isoalantolactone from Inularacemosa. Crop Protection 25(5):508-511.

[14]. Law- Ogbomo, K. E. and Enobakhare, D. A. 2007. The use of leaf powders of Ocimumgratissimum and Vernoniaamygdalina for the management of Sitophilusoryzae (Lin.) in stored rice. Journal ofEntomology, 4(3): 253-257.

[15]. Mulungu, L.S., Lupenza, G., Reuben, S.O.W.M. and Misangu, R.N. 2007. Evaluation of botanical products as stored grain protectant against Maize weevil, Sitophiluszeamais, Journal of Entomology, 4. 3. 258-262.

[16]. Bouda, H., Tapondjou, L.A., Fontem, D.A. and Gumedzoe, M.Y.D. 2001, Effect of essential oils from leaves of Ageratum conyzoides, Lantana sitophilus, Chromolaenaodorata on the mortality of Sitophiluszeamais (Coleoptera, Curculionidae), Journal of Stored Products Research, Vol.37, No. 2, (April 2001), 103-109, ISSN 0022-474X. 